\title{
A 324-years temperature reconstruction from Pinus latteri Mason at highland in Chiang Mai Province, Thailand
}

\author{
PICHIT LUMYAI ${ }^{1, \vartheta}$, KRITSADAPAN PALAKIT ${ }^{1, \vartheta v}$, KHWANCHAI DUANGSATHAPORN $^{1}$, \\ KOBSAK WANTHONGCHAI ${ }^{2}$ \\ ${ }^{1}$ Department of Forest Management, Faculty of Forestry, Kasetsart University. 50 Phahonyothin Rd, Lat Yao, Chatuchak, Bangkok 10900, Thailand \\ Tel./fax.: +66-8505-60643, `email: fforpcl@ku.ac.th, ^^ fforkpp@ku.ac.th \\ ${ }^{2}$ Department of Silviculture, Faculty of Forestry, Kasetsart University. 50 Phahonyothin Rd, Lat Yao, Chatuchak, Bangkok 10900, Thailand
}

Manuscript received: 15 June 2020. Revision accepted: 5 August 2020.

\begin{abstract}
Lumyai P, Palakit K, Suangsathaporn K, Wanthongchai K. 2020. A 324-years temperature reconstruction from Pinus latteri Mason at highland in Chiang Mai Province, Thailand. Biodiversitas 21: 3938-3945. The objective of this study was to investigate the relationship between the growth of Pinus latteri and climate data in Chiang Mai Province, Thailand. Dendrochronological techniques were used to analyze 35 sample cores. The cross dated ring width data could be extended back for up to 324 years (1692-2015). The relationship between ring-width index and climate data indicated a significant correlation $(\mathrm{p}<0.01)$ with the monthly rainfall in January, monthly temperature in August and September, extreme maximum temperature in August and mean maximum temperature in March and August. The reconstructed average monthly temperature in August was estimated at around $27.35{ }^{\circ} \mathrm{C}$, a warming period could have occurred in 1694-1702, 1834-1844, 1848-1866, 1873-1876, 1884-1890, 1896-1902, 1911-1927, 1942-1958, and 1986-1990, with cooling periods occurring in 1703-1722, 1739-1752, 1865-1872, 1877-1883, 1891-1895, 1903-1910, 1928-1941, 1959-1961, and 19681970, which could explain the high fluctuations in temperature. Periods in the range 2.1-2.5, 10.1, and 13.5 years were found to be common with the variations in El Niño-Southern Oscillation. In conclusion, the pine growth information can be used to monitor the variations in climate in Thailand.
\end{abstract}

Keywords: Chiang Mai, highland, Pinus latteri, temperature reconstructions, Thailand

\section{INTRODUCTION}

Climate change is drastically affecting human activities and natural resources, especially forest resources. In order to better understand climate change and its variability, having origins either in natural or anthropogenic sources, analyzing the historical climate and its behavior over time can give indicate future variations. However, the recorded climate data is not enough to explain the climatic dynamics at local and regional scales. Therefore, other techniques are needed to study past climate scenarios. Thus, there is an increasing demand to understand the past climate response using tree-ring analysis, and has encouraged dendroclimatologists to expand their research into looking at ring formation in trees from the tropical forests (Susatya and Yansen 2016). An increasing demand for paleoclimate estimations relating to the climate of a given geologic time in the past and information about natural disasters has stimulated scientists to extend their area of study from the southern and northern temperate zones towards the equator, including Thailand. Tree-ring studies have been gradually increasing in Thailand over the past decade. Dendroclimatologists in Thailand have conducted successful climate reconstruction studies using teak (Tectona grandis) and pine (Pinus spp.) (Pumijumnong and Wanyaphet 2006; Buckley et al. 2007; Pumijumnong and Eckstein 2011; Palakit et al. 2015, 2016; Buajan et al. 2016; Muangsong et al. 2016, 2018; Lumyai and
Duangsathaporn 2017a,b; Preechamart et al. 2018; Yordtong et al. 2019; Rakthai et al. 2020; Buareal et al. 2020). They discovered that pine species and variation in teak ring width was related to changes in temperature and rainfall and strong relationship with the regional climate data of the Equatorial Southern Oscillation Index and the Equatorial Sea Surface Temperature. There are 2 native pine species in Thailand, which include Pinus latteri (Tenasserim pine) and Pinus kesiya. The Tenasserim pine is widely distributed in Southeast Asia and is considered as one of the most important tree species for reforestation of watershed areas. In Thailand, natural $P$. latteri forests are mainly distributed in the northern and northeastern regions. Nowadays, most of the remaining pine forests are mostly confined to the protected areas, i.e., national parks and wildlife sanctuaries. However, there is a natural pine forest outside such protected areas, namely the Wat Chan Pine Forest, located in Galyani Vadhana District, Chiang Mai, Thailand which is under the Ban Wat Chan Royal Project and the Forest Industry Organization (FIO). Climate reconstruction through dendrochronological analyses for time periods, prior to the existence of meteorological records, can be used to devise sustainable management of natural forests and plantations. The objective of the study was to investigate the relationships between tree-growth and climatic data in Pinus latteri growing at highlands in the Chiang Mai province in northern Thailand. The aim was to demonstrate the potential use of climatic reconstruction in Thailand. 


\section{MATERIALS AND METHODS}

\section{Study area}

Wat Chan Pine Forest is located in Galyani Vadhana District, Chiang Mai Province, Thailand which is under the responsibility of "Ban Wat Chan Royal Project" and the "Forest Industry Organization" (FIO) is located at an average elevation of 900-1200 m a.s.l. (Figure 1.A). The agricultural research area at the station covers an area of approximately 151,833 rai (24293.28 ha), which includes nine villages. The government has been financially supporting the efforts to conserve and restore this pine forest through the FIO activities since 1997. Recently, around 3,040 hectares of the natural forest cover at Ban Wat Chan has been restored using the participation of the local community, while 224 hectares of pure native pine plantation stands was established and is maintained by the FIO (Northern Silvicultural Research Center. 2019, Wat Chan Royal Project Development Center 2019). Furthermore, Ban Wat Chan has cool weather throughout the year, with an average temperature of $18{ }^{\circ} \mathrm{C}$ (Ban Wat Chan Royal Project 2018). The tree-ring data used for this study was obtained from the Wat Chan Royal Project Development Center (Huai Ngoo substation). It is located at latitude $2107530 \mathrm{~N}$ and longitude 429121E. The local climate data for the period of 1951 to 2015 were published by the Thai Meteorological Department, including total monthly rainfall, mean monthly relative humidity, mean monthly temperature (Tmean), extreme maximum monthly temperature (TEmax), extreme minimum monthly temperature (TEmin), mean maximum monthly temperature (TMmax), and mean minimum monthly temperature (TMmin), were measured at the Mae hong son meteorological station (latitude $2134346 \mathrm{~N}$ and longitude 391434E ), which is located nearest (around $45 \mathrm{~km}$ from the study location) to the study site (Figure 1.B).

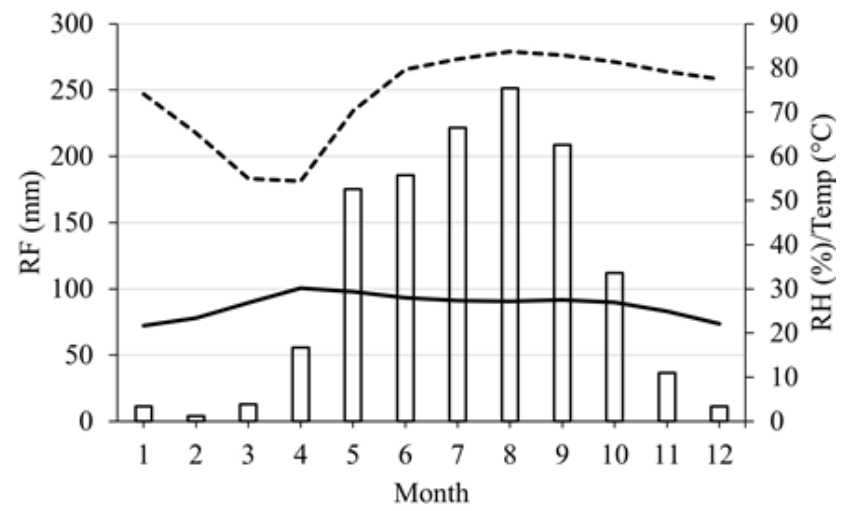

$\square$ Rainfall (mm) —-Temperature $\left({ }^{\circ} \mathrm{C}\right)$ - -- Relative Humidity (\%)

B

Figure 1.B. The local climate data, including total monthly rainfall, mean monthly relative humidity, mean monthly temperature was published by the Thai Meteorological Department.
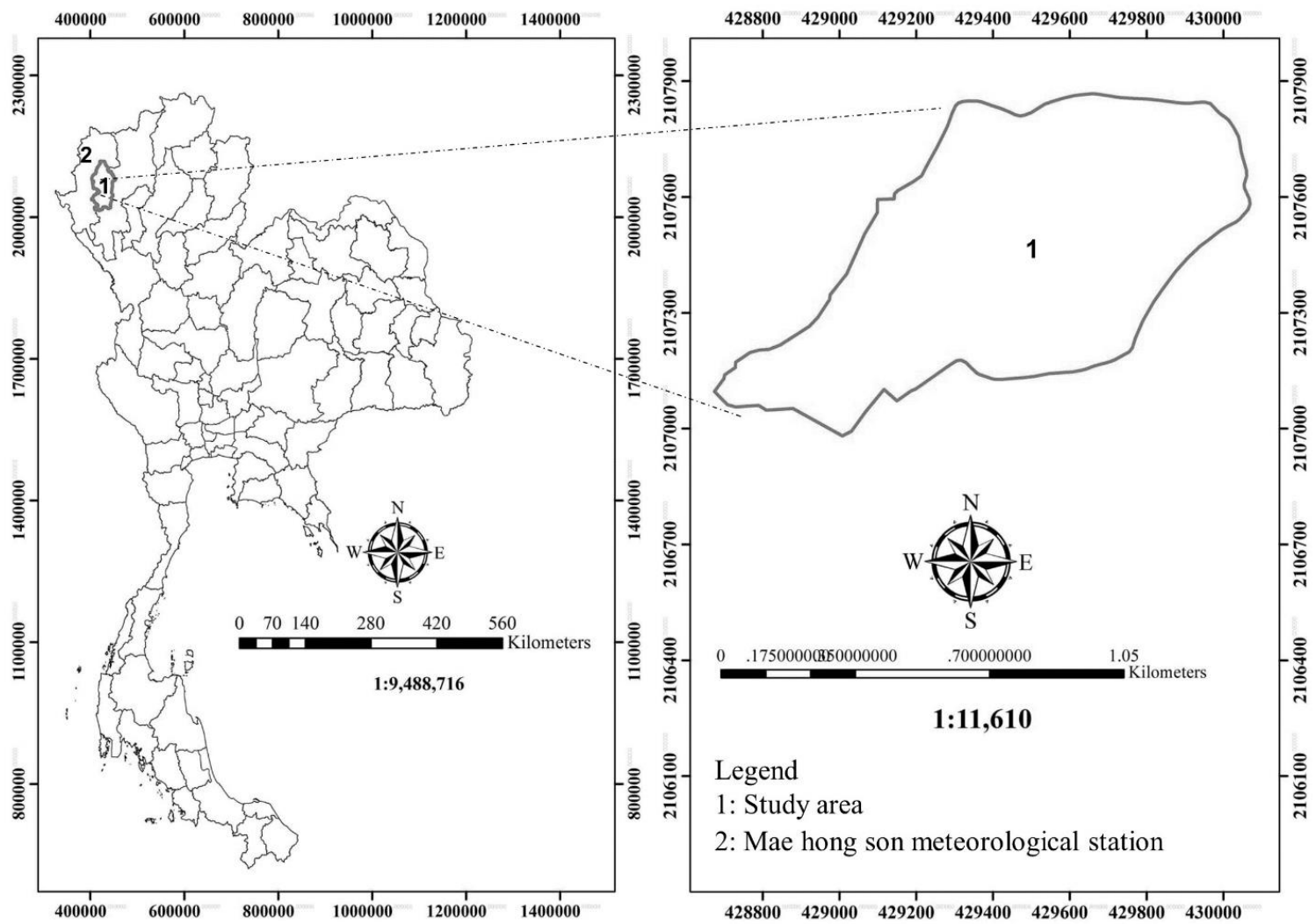

A

Figure 1. A. Map of Thailand showing the location of the Pinus latteri Mason study site; Wat Chan Royal Project Development Center (Huai Ngoo substation) (WJ) and the Mae hong son meteorological station (MH) 


\section{Sample collection}

The Pinus latteri Mason increment core samples from 20 living trees were collected in 2016, with two cores sampled from each tree, in the opposite directions of the tree and across the slope. Specific dominant trees were selected for sampling to best target the oldest trees (i.e., trees with the largest diameter at breast height, $\mathrm{DBH}$ ) so as to avoid obvious bruises, scars, and other effects such as fire or insect damage. In the laboratory, All core specimens were prepared following the standard methods of dendrochronology (Stokes and Smiley 1968). all samples were dried, glued, and mounted onto wooden supports with the cross-section (transverse view) facing upward. The mounted cores were then sanded to 1,000 grit (roughly 1822 microns), until the boundary of each annual ring was clearly visible.

Ring width measurement and tree-ring index construction

The tree-rings were identified as either annual rings, false rings, or missing rings by using the techniques of visual cross-matching (Fritts, 1976). After a successful visual cross-dating of the ring width time series, the annual ring widths were measured using the TA Unislide TreeRing Measurement System (Velmex Inc., New York, USA), with an accuracy of $0.001 \mathrm{~mm}$ and a $4 \mathrm{x}-40 \mathrm{x}$ stereo microscope. The Velmex system was interfaced directly to a microcomputer, to record the measurements. Correlation statistics were used to evaluate the accuracy of the visual cross-dating using the COFECHA program (Holmes 1983). The ring width time series thus produced were analyzed using the general statistical tools used in dendrochronological studies, specifically series intercorrelation, standard deviation, and mean sensitivity (Fritts, 1976). Next, the standardization of ring-width measurements is necessary to remove the decrease in the ring width size associated with age and to allow fastergrowing trees to be directly compared with slower growing trees. A standardized ring-width series called a ring-width index was constructed using the program ARSTAN, with the default settings. The chronological signal strength was also evaluated in order to estimate the acceptable number of the population and to measure the average correlation between ring-width series, using the calculated expressed population signal (EPS) and the running mean series intercorrelation (Rbar), respectively. An EPS value of > 0.85 was defined as acceptable for a noise-free chronology. (Wigley et al. 1984; Cook and Kairiukstis 1990).

\section{Climate-growth response analysis, climate reconstruction, and spectral analysis.}

The local climate data were published by the Thai Meteorological Department and The regional climate data of the Southern Oscillation Index (SOI) and the Sea Surface Temperature (SST) obtained from https://www.esrl.noaa.gov/psd/data/climateindices/, were regressed against the ring-width chronology, using a simple linear regression with the ring-width data as the dependent variables and the climatic data as the independent variables. The climate variables for the reconstruction were chosen on the basis of the response function. The data were divided into an early period and a later period in order to assess the temporal model stability of the identified underlying model. Calibration-Verification statistics, commonly used in dendroclimatology (Cook and Kairiukstis 1990), was calculated to confirm the model reliability. The statistics included Pearson's correlation coefficient ( $r)$, the coefficient of determination $\left(r^{2}\right)$, the verification reduction of error statistic (RE), the verification coefficient of efficiency (CE), the product means test (Pmt), and the sign test (ST) (s being number of incorrect signs) (Fritts 1976; Cook et al. 1994). The tests were computed using the verify routine (VFY), available in the Dendrochronology Program Library (DPL) software (Holmes 1994). Spectral analysis (Jenkins and Watts 1969) was used to evaluate the frequency domain properties of the reconstructed signal using the REDFIT procedure (Schulz and Mudelsee 2002).

\section{RESULTS AND DISCUSSION}

\section{Crossdating assessment and chronology development}

Attempts were made to visually cross-date all the samples after inspection for non-annual growth bands (for e.g., false rings, also called inter-annual density fluctuations and missing (locally absent) rings). Cores from Pinus latteri Mason were successfully cross-dated visually and this cross-dating was verified using the COFECHA program (Holmes 1983). These sample cores passed the significance test at a $99 \%$ confidence level and a Pearson correlation coefficient of 0.3281 . A total of 35 cores from 18 trees were successfully cross-dated. The cross-dated ring-width data was extended back 324 years, covering a period from 1692 to 2015, as shown in Figure 2.A. The mean series intercorrelation, average mean sensitivity, standard deviation, autocorrelation, and mean length of series, as obtained from COFECHA program were 0.477 , $0.289,0.667,0.690$, and 174.7 years, respectively. The mean ring-width value was $0.113 \mathrm{~cm}$ per year.

Standardized ring-width series, also called the ringwidth index, was obtained after dividing the ring-width by the value obtained from the fitted curve for a particular year (Cook and Peters 1981, Fritts 1976). These procedures were done using the ARSTAN program (Cook 1985). The ring-width index indicated a rapid growth during the period from 1930-1953 and a continuous decrease until 1973. The later growth rate seemed to be stable until the present time (Figure 2.B). We quantified the signal strength of the chronology using the EPS (Wigley et al. 1984), which indicates how well the study site chronology can estimate a theoretically infinite population. The part of the chronology, where the replication (n) was sufficient to accomplish an EPS $\geq 0.85$ was accepted as a reliable chronology for tree-ring analysis, and was regarded as a dependable proxy for climate reconstruction. The running Rbar (Cook and Kairiukstis 1990), which measures the correlation between ring-width series through time, was also calculated. However, the period from 1692-1750 had a low sample depth and was less reliable in estimating the mean annual growth (Figure 2.C). 


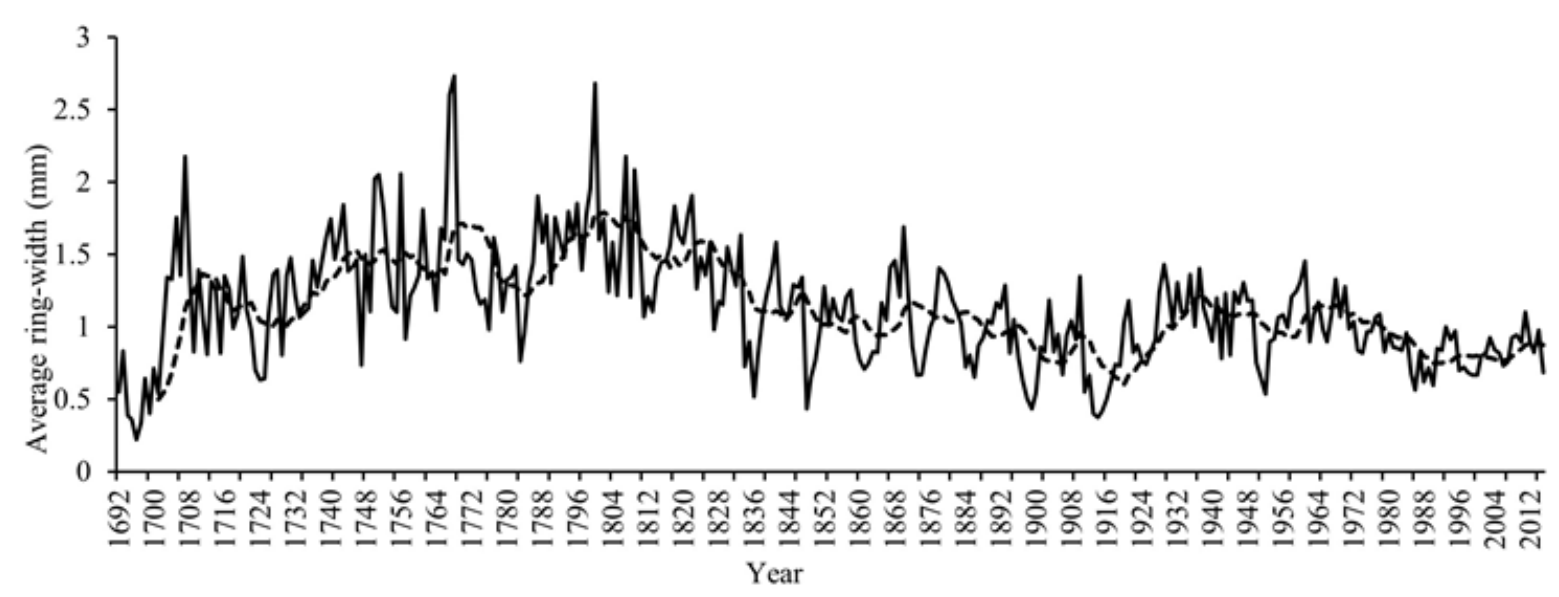

A

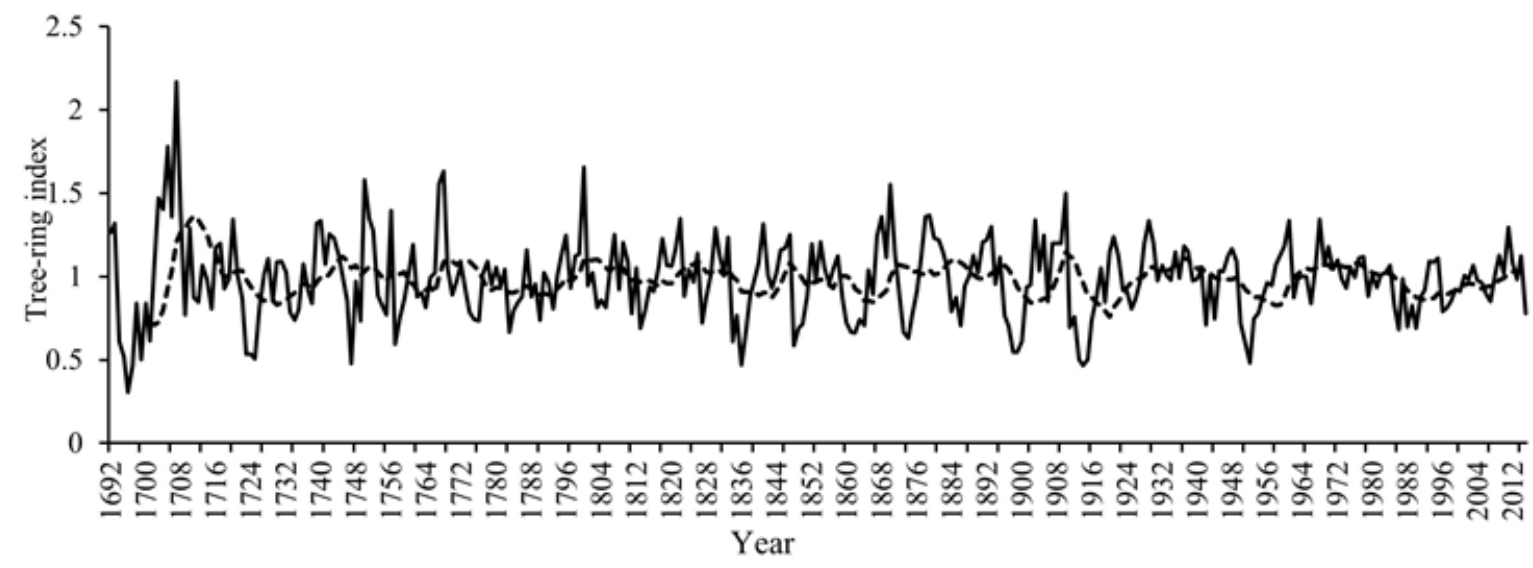

B

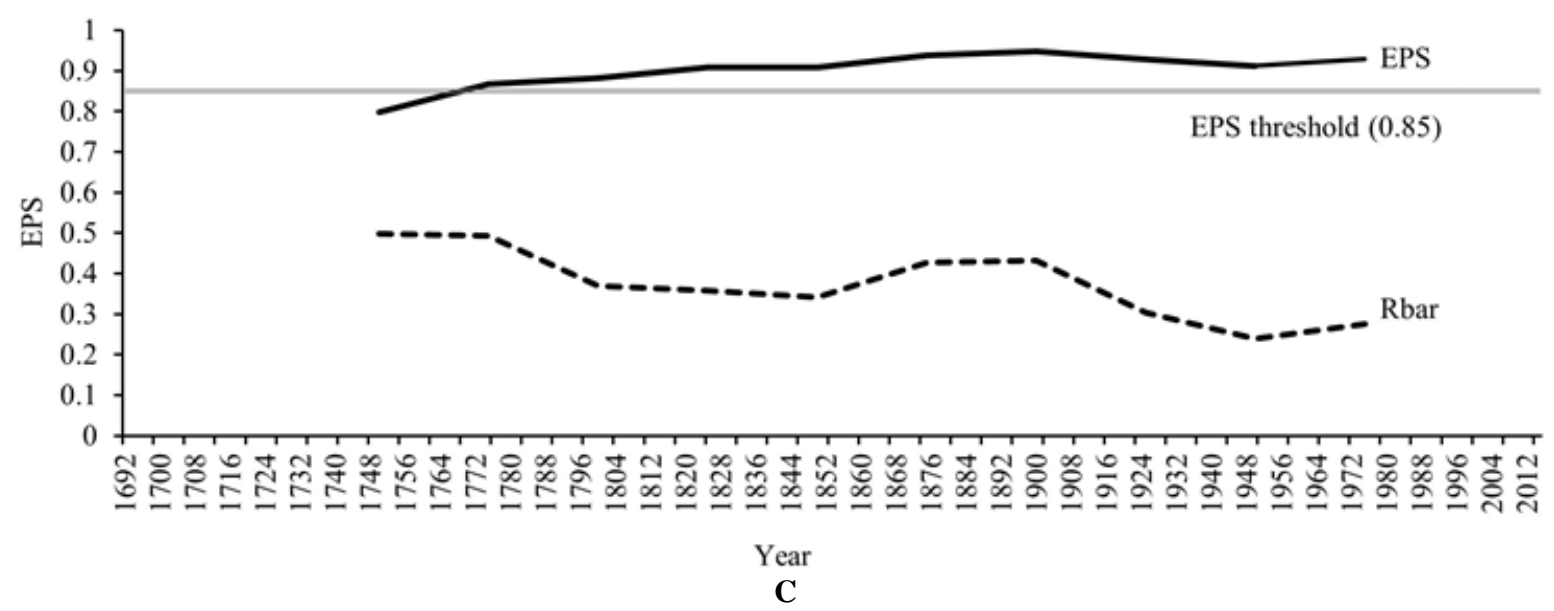

Figure 2. A. Mean ring-widths of Pinus latteri from Wat Chan Royal Project Development Center (Huai Ngoo substation) (plotted with a continuous line) and 10 years moving average (plotted with a dashed line). B. The standardized chronological index (plotted with a continuous line) and its 10 -year moving average (plotted with a dashed line). C. Running EPS statistic and Rbar of tree-ring index which was accepted as a reliable chronology for tree-ring analysis

\section{Climate response}

In order to identify the relationship between growth and climate, data from the nearest meteorological station (Table 1) were correlated with each standardized tree-ring chronology. The Pinus latteri chronology indicated a strong significant positive correlation $(\mathrm{P}<0.01)$ with rainfall in January $(\mathrm{r}=0.328)$ and significant positive correlation $(\mathrm{P}<0.05)$ with rainfall and relative humidity in August $(\mathrm{r}=$ 0.263 and 0.290 , respectively). The chronology showed a strong significant negative correlation $(\mathrm{P}<0.01)$ with Tmean in August and September ( $\mathrm{r}=-0.453$ and -0.362 , respectively) and a negative correlation $(\mathrm{P}<0.05)$ with the 
Tmean in March $(\mathrm{r}=-0.281)$. The chronology had a strong significant negative correlation $(\mathrm{P}<0.01)$ with the TEmax in August $(\mathrm{r}=-0.392)$ and a negative correlation $(\mathrm{P}<0.05)$ with the TEmax in January, March, May, and September ( $\mathrm{r}$ $=-0.317,-0.313,-0.268$, and -0.299 , respectively). TEmin was negatively related to the growth of pine. The chronology had a strong significant negative correlation $(\mathrm{P}<0.01)$ with the TMmax in March and August $(\mathrm{r}=-0.340$ and-0.400, respectively) and a negative correlation $(\mathrm{P}<0.05)$ with the TMmin in January and September $(\mathrm{r}=-$ 0.307 and-0.313, respectively) and was negatively correlated with the Tmmin in January $(r=-0.322)$. It was also found that the monthly rainfall in January of the previous year had positive correlation $(\mathrm{r}=0.313, \mathrm{P}<0.05)$ with the tree-ring index. The chronology had a significant negative correlation with Tmean in March, August, September, and October ( $\mathrm{r}=-0.290,-0.288,-0.300$ and0.261 , respectively) as well as the TMmax in August ( $\mathrm{r}=-$ 0.262 ) of the previous year.

To identify the regional climate-growth relationship of the pine, the Atlantic Tripole Sea Surface Temperature (SST) data (1948-2015) were correlated with the tree-ring chronology. The chronology showed a strong significant negative correlation $(\mathrm{P}<0.01)$ with the SST in July $(\mathrm{r}=$ $0.354)$, and negative correlation $(\mathrm{P}<0.05)$ with the SST in June $(r=0.282)$. Other climatic factors showed negative relationships with the growth of the pine.

\section{Climate reconstruction}

The variations in annual ring width of Pinus latteri were found to be related to the temperature, rainfall, and relative humidity, but was most strongly related to temperature. The result indicated that the current year temperature in August was the most important factor affecting the tree-ring width. Therefore, in this case, we chose the August temperature as the primary variable for climate reconstruction. The data was split into a late period (1986-2015) for calibration and an early (1954-1985) for verification (Figure 3). Linear regression was used to calculate the transfer function for the reconstruction of temperature in August from the tree ring chronology (19862015). The model for the reconstructed temperature can be mathematically represented as:
$\mathrm{Y}^{\mathrm{t}}=28.828-1.5032 \mathrm{Xt}$ (eq. 1)

Where; $\mathrm{Y} t$ is the estimated August temperature value and $\mathrm{Xt}$ is the corresponding value of the tree-ring index $(\mathrm{t}$ indicates year in both cases).

The actual and reconstructed data were compared and the calibration-verification statistics was calculated. The statistical values of the calibration period indicated a significant correlation coefficient $(\mathrm{r}=0.475, \mathrm{P}<0.01)$, reduction of error statistic $(\mathrm{RE}=0.22)$, product means test $(\mathrm{PM}=3.144)$, and the value of sign test $(\mathrm{s}=9)$ as being significant. The verification period statistical values had a significant correlation coefficient $(\mathrm{r}=0.245, \mathrm{P}<0.05)$, reduction of error statistic $(\mathrm{RE}=0.242)$, the product means test $(\mathrm{PM}=1.447)$, and sign test $(\mathrm{s}=9)$. Using the reconstruction model equation (Eq. 1), we reconstructed the temperature during August in northern Thailand from 1692 to 2015, with the reconstructed average August temperature of $27.35{ }^{\circ} \mathrm{C}$ and could also explain the high fluctuations in temperature. The pointer years (extreme growth fluctuations) of warm periods and cool periods derived using the Cropper's method (Cropper 1979; Palakit et al. 2015). The trends in the reconstructed temperature indicated to warm periods during the years 1694-1699, $1701,1709,1723-1725,1733-1734,1747,1749,1755$, $1757-1758,1774-1776,1783-1784,1790,1811,1813-$ $1814,1827,1834-1837,1848-1850,1860-1864,1873-$ $1875,1884,1886,1896-1900,1911-1916,1942,1944$, 1950-1954, 1986, 1988, 1990, 1996, 2015 and in cool period during 1692-1693, 1703-1710, 1716-1717, 1720, $1739-1740,1742-1743,1750-1752,1756,1761,1767-$ $1768,1796,1800,1807,1809,1818,1821-1822,1830$, $1833,1841,1846-1847,1852,1854,1867-1868,1870$, 1878-1881, 1891-1893, 1903, 1905, 1907-1910, 1921, 1928-1930, 1937, 1948, 1960-1961, 1968, 1970, and 2011.

Based on the reconstructed temperature in August, derived from the spectral analysis, the tree-ring index indicated to a temperature cycle of 2.1-2.5 years. Significant peaks were also observed around 10.1 and 13.5 years (Figure 4).

Table 1. Measured climate data at the Mae hong son meteorological station and the correlation coefficients of Pinus latteri tree-ring index with the total monthly rainfall, mean monthly relative humidity, mean monthly temperature (Tmean), extreme maximum monthly temperature (TEmax), extreme minimum monthly temperature (TEmin), mean maximum monthly temperature (TMmax), and mean minimum monthly temperature (TMmin)indicating a significant correlation with the current year

\begin{tabular}{|c|c|c|c|c|c|c|c|c|c|c|c|c|}
\hline Character & Jan & Feb & Mar & Apr & May & Jun & Jul & Aug & Sep & Oct & Nov & Dec \\
\hline Rainfall & $.328^{* *}$ & -.184 & .165 & .098 & -.036 & -.016 & .127 & $.263^{*}$ & .175 & .080 & -.242 & -.030 \\
\hline Relative humidity & .226 & .155 & .247 & .249 & .070 & .100 & .064 & $.290^{*}$ & .172 & .133 & -.153 & .043 \\
\hline Tmean & -.002 & -.140 & $-.281^{*}$ & -.221 & -.150 & -.243 & -.152 & $-.453^{* *}$ & $-.362^{* *}$ & -.190 & .018 & .044 \\
\hline TEmax & $-.317^{*}$ & -.230 & $-.313^{*}$ & -.210 & $-.268^{*}$ & -.155 & -.144 & $-.392^{* *}$ & $-.299^{*}$ & -.182 & -.092 & -.015 \\
\hline TEmin & .167 & .022 & -.012 & -.099 & .111 & .018 & .242 & -.051 & .222 & -.020 & -.027 & .042 \\
\hline TMmax & $-.307^{*}$ & -.223 & $-.340^{* *}$ & -.202 & -.122 & -.212 & -.139 & $-.400^{* * *}$ & $-.313^{*}$ & -.173 & .107 & -.082 \\
\hline TMmin & $.322^{*}$ & .056 & -.005 & -.035 & .016 & .073 & .078 & -.059 & .017 & .032 & -.018 & .161 \\
\hline
\end{tabular}

Note: *represents significant value at 0.05 level and ** represents significant value 0.01 level 


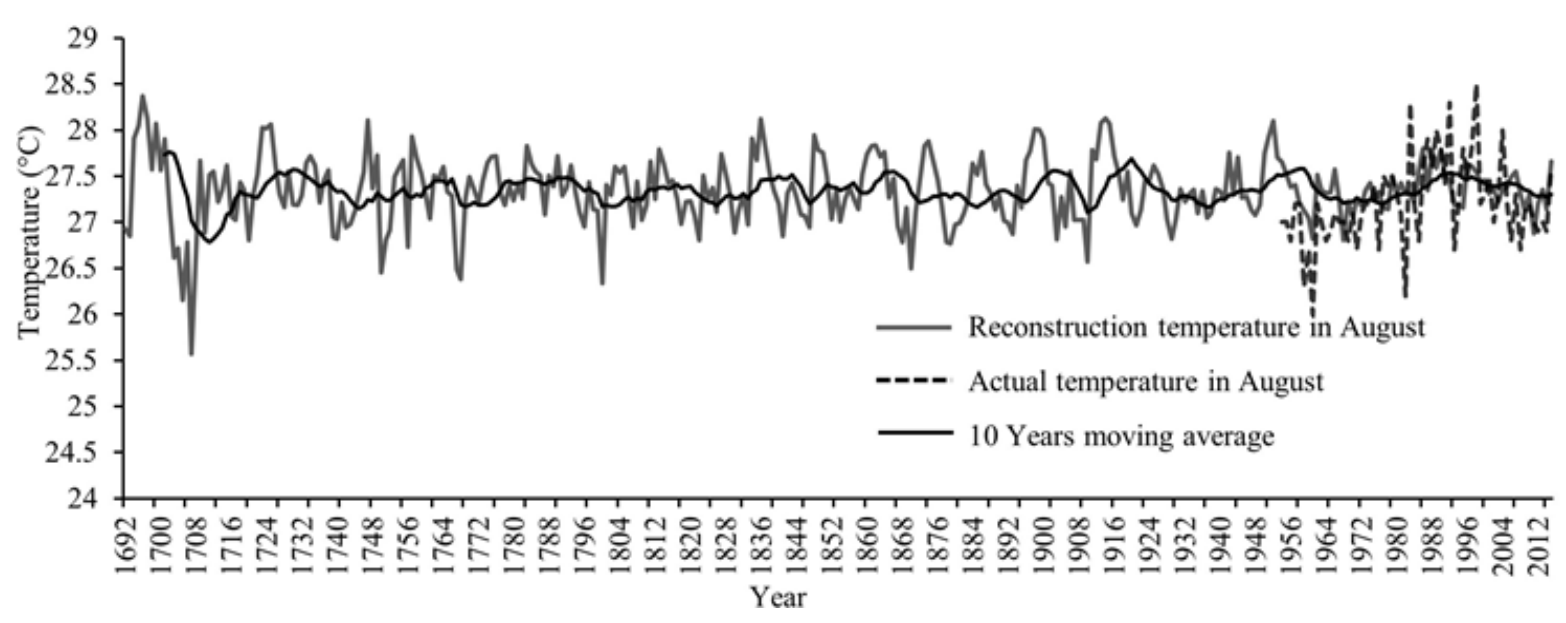

Figure 3. Reconstructed temperature in August. The late periods from 1986 to 2015 for calibration and an early period from 1954 to 1985 for verification

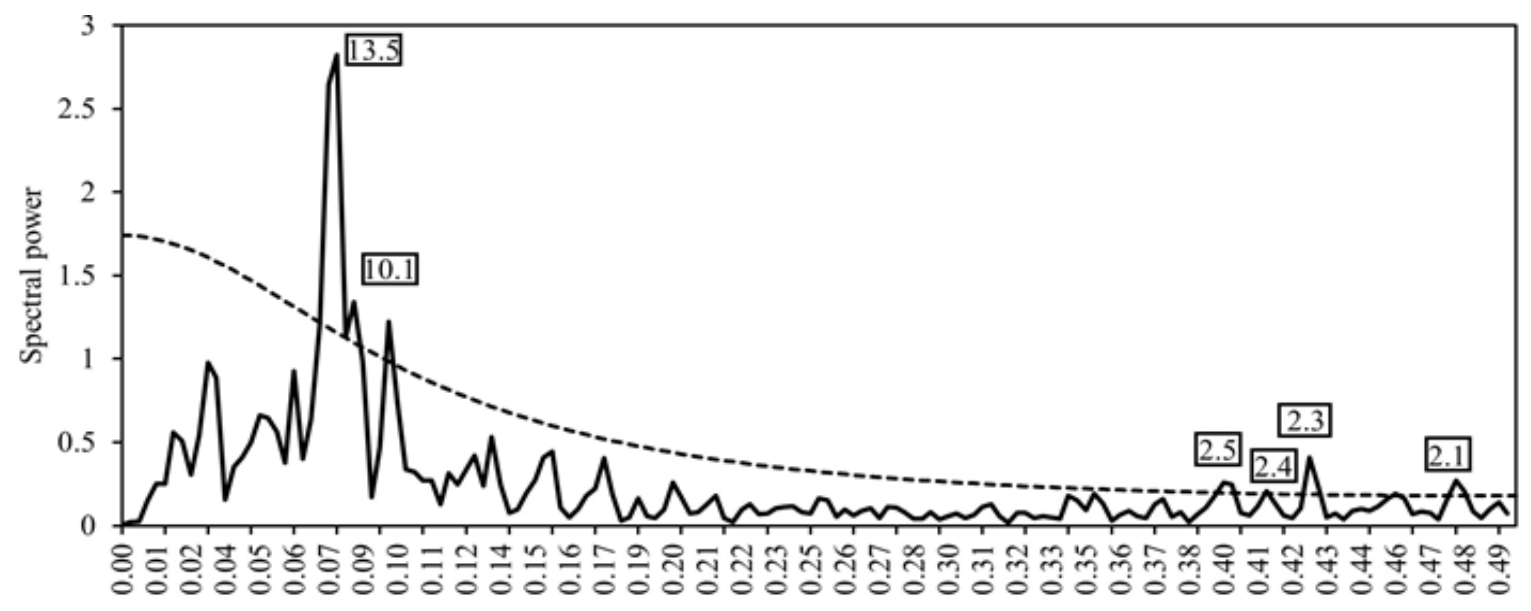

Frequency (cycles/year)

Figure 4. The power spectra of the reconstructed temperature in August using the REDFIT procedure (Schulz and Mudelsee 2002). Peaks above the dashed line are deemed significant at a 95\% level of confidence $(\mathrm{P}<0.05)$

\section{Discussion}

Climate-related growth response studies of pine trees in Thailand have indicated considerable variability in the results. In a study done in the northern region, Hutameta and Pumijumnong (2003) found a positive correlation between rainfall in March and April and the growth of Pinus latteri. Pumijumnong and Wanyaphet (2006) studied the seasonal cambial activity and tree-ring formation of Pinus latteri and of P. kesiya and found that Pinus latteri had a significant positive correlation with rainfall in the transition season and a negative correlation with temperature in the remaining months. In the northeastern region, Buckley et al. (1995) and Duangsathaporn and Palakit (2013b) reconstructed 124 years chronology of Pinus latteri growing in the Pha-taem National Park, in the easternmost reaches of Thailand. The first epoch segment from 1882-1987 indicated to a significantly positive response to the forcing from Tropical Pacific Sea Surface
Temperature (SST) in July of the current year. The later segment from 1988-2005 indicated a significant positive response to Southern Oscillation Index (SOI) in February of the current year. Yordtong et al. 2019 reconstructed a 129-year chronology of Pinus latteri and found that the monthly average minimum temperature in October and the monthly average relative humidity in March, October, and November were significantly correlated $(\mathrm{p}<0.05)$ and the monthly average relative humidity in February and the monthly average maximum temperature average relative humidity in March of the previous year had a significant correlation $(\mathrm{p}<0.01)$ with the tree-ring index. In central Thailand, Lumyai and Duangsathaporn (2017a) reconstructed a Pinus merkusii chronology extending 230 years back in time. The chronology also had a high positive correlation $(\mathrm{p}<0.01)$ with the current year temperature in October, the present year average temperature, and the previous year average temperature. Rakthai et al. (2020) 
found that the growth of Pinus latteri at three sites had a significantly positive correlation with precipitation, relative humidity, and self-calibrated Palmer Drought Severity Index during the dry season and early rainy season, and significant negative correlation with temperatures (mean, maximum, and minimum) from April to August. Pumijumnong and Palakit (2020) reconstructed a 191-year chronology of Pinus merkusii growing in central Thailand and found that the extreme maximum temperature in April was the main driver inducing intra-annual ring formation. Formation in other species across several countries also indicates to temperature is the main factor leading to growth. Wang et al. (2015) studied Korean pines growing in northeast Asia and reported that temperature is the key limiting factor in controlling the growth of Korean pine. Shi et al. (2010) developed a tree ring chronology of Sabina tibetica located in Zaduo, Qinghai Province, China, and found a significant negative correlation with the mean maximum air temperature during May and June. In the southeastern Tibetan Plateau, it was reported that winter temperature is the major growth factor of the pine sp. trees (Liang et al. 2016; Huang et al. 2019; Li et al. 2020)

In this study, the current year temperature during August was the most important factor related to the ring width index of Pinus latteri. On the other hand, other climatic factors, for example, total monthly rainfall in January and August and average monthly relative humidity in August, had a positive relationship with the growth of Pinus latteri. However, the mean temperature, extreme maximum temperature, and mean maximum temperature was had a significant negative correlation with the index. Thus, it appears that the growth of Pinus latteri can be explained by temperature changes. This result is different from the previous studies in Thailand because climatic data at this study site indicates a different pattern from the other study sites. In August, the total monthly rainfall and the monthly average relative humidity peaked with an average number of rain days is estimated at 25. However, the average temperature dropped from July onwards. The results showed that the current year temperature in August was the limiting factor affecting the tree-ring widths in this highland. The reconstruction of August temperature indicated to an average temperature of $27.35{ }^{\circ} \mathrm{C}$. A warm period occurred during the years 1694-1702, 1834-1844, 1848-1866, 1873-1876, 1884-1890, 1896-1902, 1911-1927, 1942-1958, and 1986-1990, cooling periods during in the years 1703-1722, 1739-1752, 1865-1872, 1877-1883, 1891-1895, 1903-1910, 1928-1941, 1959-1961, and 19681970, which could explain the high fluctuations in temperature of Thailand. Finally, the spectral analysis of the tree-ring index revealed a temperature cycle of 2.1-2.5 years, with significant peaks occurring around 10.1 and 13.5 years, which could be related to the influence of SST data indicated to a temperature cycle of 2.0-2.1 years.

\section{ACKNOWLEDGEMENTS}

The authors wish to thank Dr. Tushar Andriyas, currently a post-doctoral fellow at Chulalongkorn
University, Thailand, for editing this manuscript. This study was supported by The Laboratory of Tropical Dendrochronology, Department of Forest Management, Faculty of Forestry, Kasetsart University, Bangkok, Thailand, and the Royal Project Foundation of Thailand and Highland Research and Development Institute (Public Organization).

\section{REFERENCES}

Buajan S, Pumijumnong N, Li Q, Liu Y. 2016. Oxygen isotope of teak tree-rings in North-West Thailand. J Trop For Sci 28 (4): 396-405.

Buareal K, Buajan S, Preechamart S, Muangsong C, Pumijumnong N. 2020. A 177 Years Extended of Teak Chronology Revealing to the Climate Variability in Phrae Province, Northern of Thailand. App Envi Res 42 (1): 85-100.

Buckley BM, Barbetti M, Watanasak M, D'Arrigo R, Boonchirdchoo S, Saratunon S. 1995. Dendrochronological investigations in Thailand. IAWA J 16: (4): 393-409.

Buckley BM, Duangsathaporn K, Palakit K, Butler S, Syhapanya V, Xaybouangeun N. 2007. Analyses of growth rings of Pinus merkusii from Lao P.D.R. For. Ecol. Manag. 253: 120-127.

Cook ER, Kairiukstis LA. 1990. Methods of Dendrochronology. Kluwer, Dordrecht.

Cook ER. 1985. A Time Series Analysis Approach to Tree-Ring Standardization. [Dissertation]. University of Arizona, Tucson.

Cropper JP. 1979. Tree-ring skeleton plotting by computer. Tree-Ring Bull 39: 47-59.

D’Arrigo R, Barbetti M, Watanasak M, Buckley BM, Krusic PJ, Boonchirdchoo S, Sarutanon S. 1997. Progress in dendroclimatic studies of Mountain pine in Northern Thailand. IAWA J 18 (4): 433 444.

Duangsathaporn K, Palakit K. 2013. Climatic Signals Derived from the Growth Variation and Cycles of Pinus merkusii in Easternmost Thailand. Thai J For 32 (1): 9-23.

Fritts HC. 1976. Tree Ring and Climate. Academic Press, San Francisco.

Holmes RL. 1983. Computer-assisted quality control in tree-ring dating and measurement. Tree-Ring Bull 43: 69-78.

Huang R, Zhu H, Liang E, et al. 2019. A tree ring-based winter temperature reconstruction for the southeastern Tibetan Plateau since 1340 CE. Clim Dyn 53: 3221-3233.

Hutameta A, Pumijumnong N. 2003. Pine tree-ring response to climate and ENSO at Ban Wat Chan, Chiang Mai. Environ Nat Resour J 1 (2): 69-76.

Li Jing, Li Jinb, Li T, Au TF. 2020. Tree growth divergence from winter temperature in the Gongga Mountains, southeastern Tibetan Plateau. Asian Geogr. 37 (1): 1-15.

Liang H. Lyu X, Wahab M. 2016. A 382-Year Reconstruction of August Mean Minimum Temperature from Tree-Ring Maximum Latewood Density on the Southeastern Tibetan Plateau, China. Dendrochronologia 37: 1-8.

Lumyai P, Duangsathporn K. 2017a. Pine growth variation and climate change: Opportunities for dendroclimatology in central Thailand. J Trop For Res 1 (1): 23-35.

Lumyai, P, Duangsathaporn K. 2017b. Climate Reconstruction on the Growth of Teak in Umphang Wildlife Sanctuary, Thailand. Environ Nat Resour J 16 (1): 21-30.

Muangsong C, Cai B, Pumijumnong N, Hu C, Lei G. 2016. Intra-seasonal variability of teak tree-ring cellulose $\delta 18 \mathrm{O}$ from northwestern Thailand: A potential proxy of Thailand summer monsoon rainfall. Holocene 26: 1397-1405.

Muangsong C, Cai B, Pumijumnong N, Lei G, Wang F. 2018. A preliminary study on teak tree ring cellulose $\delta 180$ from Northwestern Thailand: The potential for developing multiproxy records of thailand summer monsoon variability. Theor Appl Climatol 136: 575-586.

Northern Silvicultural Research Center. 2019. 50 years Pine. Northern Silvicultural Research Center Division of Research Forest Research and Development Office Royal Forest Department, Bangkok.

Palakit K, Duangsathaporn K, Siripatanadilok S, Lumyai P. 2015. Effects of climate variability on monthly growth of Aglaia odoratissima and Hydnocarpus ilicifolia at the Sakaerat Environmental Research 
Station (SERS), Northeastern Thailand. Environ Nat Resour J 13: (1): $1-12$.

Palakit K, Duangsathaporn K, Siripatanadilok S. 2016. Climatic fluctuations trigger false ring occurrence and radial-growth variation in teak (Tectona grandis L.f.). iForest-Biogeosci For 9: 1-8.

Preechamart S, Pumijumnong N, Payomrat P, Buajan S. 2018. Variation in climate signals in teak tree-ring chronologies in two different growth areas. Forests 9 (12): 772.

Pumijumnong N, Eckstein D. 2011. Reconstruction of pre-monsoon weather conditions in northwestern Thailand from the tree-ring widths of Pinus merkusii and Pinus kesiya. Trees 25 (1): 125-132.

Pumijumnong N, Palakit K. 2020. Effects of climate variability on the annual and intra-annual ring formation of Pinus merkusii growing in Central Thailand. Environ Nat Resour J 18 (3): 234-248.

Pumijumnong N, Wanyaphet T. 2006. Seasonal cambial activity and treering formation of Pinus merkusii and Pinus kesiya in northern Thailand in dependence on climate. For Ecol Manag 226 (1): 279 289.

Rakthai S, Fu PL, Fan ZX, Gaire NP, Pumijumnong N, Eiadthong W, Tangmitcharoen S. 2020. Increased drought sensitivity results in a declining tree growth of Pinus latteri in Northeastern Thailand. Forests 11 (3): 2-18

Shi X, Qin N, Zhu H, et al. 2010. May-June mean maximum temperature change during 1360-2005 as reconstructed by tree rings of Sabina Tibetica in Zaduo, Qinghai Province. Chin Sci Bull 55: 3023-3029 (2010).

Stokes MA, Smiley TL. 1968. An Introduction to Tree-Ring Dating. University of Chicago Press, Chicago, IL.

Susatya A, Yansen Y. 2016. Dendrochronology of young Swietenia macrophylla and the variation of its growth response to the past wet climate in Bengkulu, Indonesia. Biodiversitas 17 (2): 446-472.

Wang X, Zhang M, Ji Y et al. 2017. Temperature signals in tree-ring width and divergent growth of Korean pine response to recent climate warming in northeast Asia. Trees 31 (2): 415-427.

Wat Chan Royal Project Development Center. 2020. Wat Chan Royal Project Development Center, Chiang Mai. http://royalprojectthailand.com/sites/default/files/WatChanEng_0.pdf. [6th August 2020].

Yordtong K, Duangsathaporn K Palakit K. 2019. Climatic factors on growth of Pinus latteri Mason in Hill evergreen forest at Phu Kradueng National Park, Loei Province. Thai J For 38 (2): 124-135. 